\title{
Seasonal variation of upper Blue Nile basin moisture budget and the global moisture dynamics in the role of spatiotemporal precipitation variability
}

\author{
Megbar. W. Birhan ${ }^{1,2, *}$, U.Jaya Prakasha Raju² and Samuel.T. Kenea ${ }^{3}$ \\ ${ }^{1}$ Department of physics, Science College, Debre Markos University, Debre Markos, Ethiopia \\ ${ }^{2}$ Washera Geospace and Radar Science Laboratory, Department of Physics, Science College, \\ Bahir Dar University, Bahir Dar, Ethiopia \\ ${ }^{3}$ Climate Research Division, National Institute of Meteorological Sciences (NIMS), Jeju-do, \\ Republic of Korea
}

*Correspondence to: megbar.radiation05@gmail.com; Tel.:+251963743407

Institutional email address: bduinfo@bdu.edu.et

\begin{abstract}
Upper Blue Nile basin (UBNB) is the water tower of Ethiopia and downstream countries. It contributes significant moistures to the surrounding atmosphere. However, the contribution of the moisture from the basin to the precipitation in the study area is not well documented. Therefore, this paper is aimed to seasonal variation of upper Blue Nile basin moisture budget and the global moisture dynamics in the role of spatiotemporal precipitation variability. To this end, we used European Centre for Medium-range Weather Forecast (ECMWF) data from 1979-2017. The ECMWF precipitation products are correlated with in-situ observations (correlation coefficient of 0.72). During the summer season most of the UBNB moisture is converted to precipitation around the central parts of the study area, while in spring it contributes to the southern parts of the study area. Whereas northwest part of the study area is affected by basin moisture during autumn season. The calculated recycling ratio for four seasons (summer, autumn, spring and winter) are $9.70 \%, 16.33 \%, 19.01 \%$, and $35.30 \%$ respectively with annual average value of $20.11 \%$. It is evident that the maximum amount of precipitation is extracted from the local moistures during winter season. Hence, we concluded that UBNB moisture budget had lesser contribution of precipitation over the study area. It rather, contributed a significant precipitation to the neighboring countries such as Egypt and Sudan. Further studies on moisture budget are required to explain this phenomenon in the context of Ethiopia.
\end{abstract}

Keywords: evaporation; moisture budget; precipitation; recycling ratio 


\section{Introduction}

Understanding of freshwater availability has an immense importance in assessing socio-economic and environmental impacts of climate and demographic change [1] and ensuring energy and food security for climate adaptation [1,2]. There is a scarcity of fresh water around the countries within Abay basin. For instance Egypt and Sudan received insufficient fresh water [3]. Upper Blue Nile basin (UBNB) is located in Ethiopia highlands, which receives up to $2000 \mathrm{~mm}$ per year [4]. It is extremely vulnerable part of the country due to the availability of sufficient precipitation, surface water and underground water [4]. Hence, precipitation is a critical factor for geomorphological, hydrological, and ecological processes [5]. Conversely at the present time, however, the scarcity of precipitation and floods with irregular frequency is occurred due to different mechanisms [6, 7].

Since, UBNB in Ethiopia is one of the areas that consist of variable topographic features. It is impossible to identify the source of moistures that contributed spatial and temporal precipitation distribution over the study domain because of the interaction between the moisture with their variable geographical features [6-9]. The source of atmospheric moisture that contributed precipitation over the study area is highly depend on Lake Tana, Nile river basins, and large scale moisture dynamics. The evaporation rate over UBNB is high because of the availability of soil moistures and water bodies [6]. The contribution of the water bodies and the soil moisture content on spatiotemporal distribution of precipitation is not well documented owing to climate change in tropics due to rising of greenhouse gases concentration over variable geographical features [8-11]. Therefore, moisture budget analysis is the only solution to evaluate the spatial and temporal distribution of precipitation. It is an attractive approach for studying precipitation generation and variability [10, 11]. Further moisture budget is useful to predict the future climate conditions [12]. Hence, for the linkages between atmospheric dynamics, water vapor conditions and precipitation are constrained by the moisture budget equation $[13,14]$.

Apart from forest and the soil, UBNB receive moistures from different air masses such as Atlantic Ocean, Indian Ocean, red see, Arebian see, Congo basin [15, 16], and the local water bodies (e.g. Lake Tana and Abay basin). UBNB in Ethiopia is a part of east African country its rainfall variability is affected by inter tropical convergence zone (ITCZ) [17]. In the winter, when the 
earth's southern hemisphere tilts towards the sun, the southern hemisphere received maximum amount of radiation [18]. Hence, gradually an ITCZ migrated from northern to southern hemisphere. As UBNB, is located in the northern hemisphere; it couldn't get sufficient rainfall during winter season. However, less amount rainfall is happened from the local moistures. The strength of wind is less than the precipitation rate and the flux becomes divergence which indicates that the source of rainfall in the study area is from the local atmospheric moistures. This can be strongly evident from outgoing long wave radiation (OLR), when the local moisture traps more OLR, its intensity decreases [19]. During summer season, the moisture dynamics is seems to be reverse of winter season. The wind blows from southwest to northeast and carry moistures from Atlantic Ocean during this season [20,21]. Most of this moisture is captured by the Ethiopian highlands (study area) when compared to the other countries owing to its mountainous features.

During recent decades, numerous studies have been published on moisture budget field by different authors in different countries. For e.g. at China by SunLi et al. [22] and Zengxin et al. [14], over Mediterranean by Fengjun et al. [10] , Jin and Zangvil [23], over Amazon Basin by Drumond et al. [24] and in Africa by Catherine et al. [25]. In Ethiopia large scale moisture dynamics is studied by number of authors $[15,16,26]$, but they did not to estimate the contribution of the study area moistures for the precipitation system. In the case of UBNB, climate and hydrology relations are addressed by Conway [27]; the spatial and temporal rainfall variability is studied by Charles and Patrick [5]; estimation of evaporation variability is studied by Mariam et al. [28] and water balance modeling is studied by Abera et al. [7].

According to previous literature survey, none is reported the contribution of UBNB moisture budget to the precipitation over the research domain. Therefore, for the first time we estimated seasonal variation of upper Blue Nile basin moisture budget and the global moisture dynamics in the role of spatiotemporal precipitation variability by investigating long term dataset from 19792017 (38 years). It also examines the variations of atmospheric moisture fields and moisture transport mechanisms over the region.

UBNB is one of the most data scarce regions due to lack of hydro-meteorological stations [6, 7]. To fill in this gap, we employed various satellite data such as climate research unit (CRU) and 
Climate Prediction Center (CPC) Merged Analysis of Precipitation (CMAP) reanalysis data and ECMWF ERA-interim data.

\section{Study area description, data and methodology}

\subsection{Study area description}

The study is conducted in the domain of the upper Blue Nile basin of Ethiopia. It is located between $7^{0} 40^{`}$ to $12^{0} 5^{`} \mathrm{~N}$ and from $34^{0} 25^{`}$ to $39^{0} 49^{`} \mathrm{E}$ with a drainage area of $176,000 \mathrm{~km}^{2}$ (Figure 1 ). Lake Tana and Abby River basin are the main water bodies in the study area. These two water bodies have a significant contribution of atmospheric moistures over study area. The basin's climate varies from humid to semiarid. The annual precipitation increases from northeast to southwest [28]. Specifically, its hydrological behavior is characterized by high spatiotemporal variability [28]. Since UBNB has the share of the total Nile flow, it is the economic mainstay of downstream countries (i.e. Sudan and Egypt) [7]. The topography of UBNB is very complex, with elevation ranging from $500 \mathrm{~m}$ in the lowlands at the Sudan border to $4160 \mathrm{~m}$ in the upper parts of the basin [27]. Due to the topographic variations, the climate of the basin varies from cold to hot, with large variations in a limited elevation range [27]. The mean annual precipitation and evaporation over UBNB are estimated to be in the ranges of 1200 to1600 mm [27] and 200 to 300 $\mathrm{mm}$, respectively. The main rain producing systems for the seasons are the global rain mechanisms, basically an ITCZ. Indian and Atlantic Oceans are the major moisture sources of African countries and that contributed precipitation during the rainy period. The period from June to September represents the major rainy season of the UBNB in Ethiopia [29].

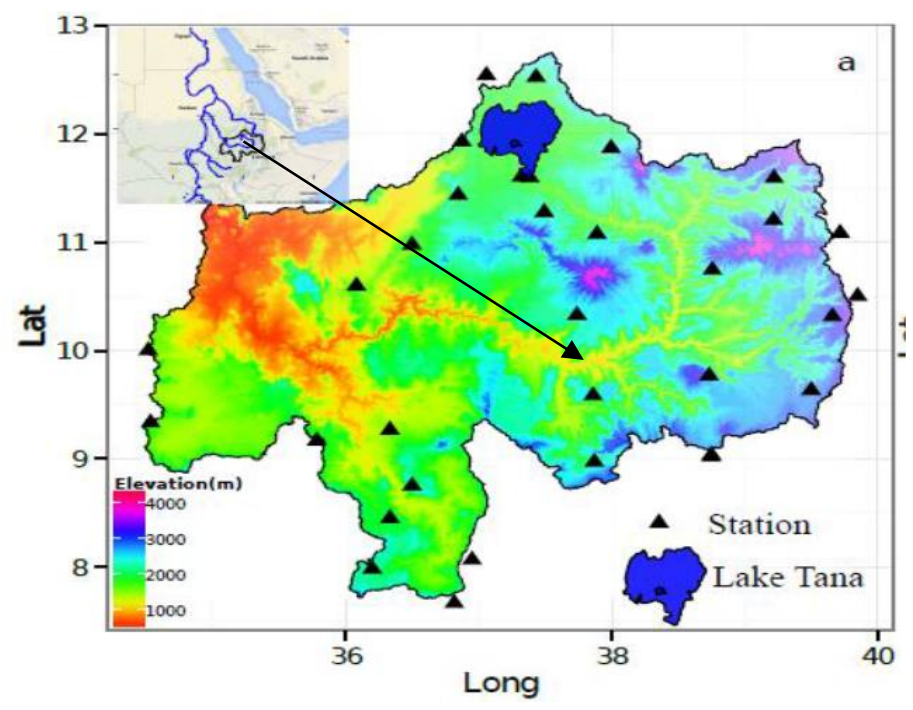


Figure 1. Location map of upper Blue Nile basin, Ethiopia [7].

\subsection{Data sources}

Precipitation observation data is obtained from a network of 20 National Meteorological Agency (NMA) stations within the UBNB at daily time scale from 2000-2014. The 20 station is selected from different locations over the study domain by considering the weather and climate conditions such as temperature zone, rainfall, altitude and forest cover. Estimating rainfall data is obtained from the weather radar reflectivity-rain rate (Z-R) relation empirical model from 22, June, 201614, July, 2016. Because of the availability of the radar data, we consider a short period time span data. The second monthly precipitation data is obtained from satellite observation (CRU gridded datasets). The spatial horizontal scale is $0.5 \times 0.5$ degree (referred to as CRU TS3.10), for the period 1901-2016. The third daily precipitation, evaporation, zonal $\mathrm{u}$ wind and mieridional $\mathrm{v}$ wind data at $10 \mathrm{~m}$ altitude and specific humidity data is obtained from ECMWF reanalysis dataset (ERAInterim) [30-32] from 1979 - 2017. The current updating grid horizontal resolution is $0.125 \times 0.125$ degree and daily time scale. ERA-Interim is based on an atmospheric model and reanalysis system with 60 pressure levels in the vertical with a top level at $0.1 \mathrm{mb}$ [31]. The fourth type of precipitation data is obtained from CMAP, the horizontal resolutions is 2.5 x 2.5 degree and temporal time scale is monthly. Another data is outgoing long wave radiation scattering and emission of microwave radiation (OLR) data is obtained from www.olr.mon.meanNOMA.nc . The spatial horizontal scale is $1 \mathrm{x} 1$ degree and temporal scale is monthly from 1974-2016. The data is analyzed using MATLAB and IRIS software.

\subsection{Methodology}

The numerical analysis for comparison of satellite and reanalysis precipitation data against gauge observation is based on a statistical error approaches. The following error metrics is helpful to evaluate the performance of satellite-based, weather radar and reanalysis products. The error analysis is utilized using statistical techniques such as bias ratio (bias), mean relative error (MRE), root mean square error (RMSE), error deviation (direct subtraction of satellite and reanalysis data from the gauge) and Pearson correlation coefficient (R) to evaluate the performances. 


$$
\begin{gathered}
\text { Bias }=\frac{\sum_{i=1}^{n} S R_{i}}{\sum_{i=1}^{n} G_{i}} \\
M R E=\frac{\sum_{i=1}^{n}\left(S_{i}-G_{i}\right)}{\sum_{i=1}^{n} G_{i}} \\
R M=\frac{\left\{\sum_{i=1}^{n}\left[S R_{i}-G_{i}-\sum_{i=1}^{n}\left(S R_{i}-G_{i}\right)\right]^{2}\right\}^{1 / 2}}{\sum_{i=1}^{n}\left[\left(S R_{i}-\overline{S R}_{i}\right)\left(G_{i}-\bar{G}_{i}\right)\right]} \\
\sqrt{\sum_{i=1}^{n}\left[\left(S R_{i}-\overline{S R}_{i}\right)^{2}\left(G_{i}-\bar{G}_{i}\right)^{2}\right]}
\end{gathered}
$$

where $\mathrm{G}$ is gauge precipitation data; $\mathrm{SR}$ is satellite and reanalysis precipitation data; $\overline{S R}$ and $\bar{G}$ are the mean of satellite-reanalysis and gauge precipitation data respectively. After cheeked the performance of reanalysis products and satellite observations with the gauge measurements ECMWF dataset is selected to analysis moisture budgets over the study domain. We were also compared the performance of ECMWF data with Z-R relation model data from the radar.

Moisture budget is calculated using the following mathematical models. Vertical integration divergence of total energy flux (VIDTEF) [33] is estimated by

$$
\operatorname{VIDTEF}(\mathrm{x}, \mathrm{y}, \mathrm{t})=-\frac{1}{g} \int_{S}^{T} q(x, y, p, t) \mathbf{V}(x, y, p, t) d p
$$

where VIDTEF is the component of $\mathrm{Q}_{\mathrm{u}}$ the zonal (east-west) and $\mathrm{Q}_{\mathrm{v}}$ is the mieridional (northsouth) of moisture transport vapor flux in $\left(\mathrm{kg} \mathrm{m}^{-1} \mathrm{~s}^{-1}\right), \mathrm{q}$ is specific humidity $\left(\mathrm{gm} \mathrm{gm}^{-1}\right), \mathbf{V}$ is a component of $\mathrm{u}$ the zonal and $\mathrm{v}$ is the meridional wind speed at $10 \mathrm{~m}$ altitude $\left(\mathrm{m} \mathrm{s}^{-1}\right)$, p is pressure level $(\mathrm{hPa})$, and $\mathrm{g}$ is the gravitational acceleration constant $\left(9.81 \mathrm{~m} \mathrm{~s}^{-2}\right)$. $\mathrm{T}$ is top pressure level which is $300 \mathrm{hPa}$ and $\mathrm{S}$ is surface pressure levels.

Perceptible water vapor ( $\mathrm{Pw}$ ) (atmospheric water vapor) is calculated by 


$$
p w=\frac{\delta}{g \delta t} \int_{S}^{T} q d p
$$

Horizontal water vapor advection (HA) (instantaneous moisture flux (IMF)) is calculated by

$$
H A=\frac{1}{g} \int_{S}^{T} \mathbf{V} . \nabla q \mathrm{dp}
$$

Horizontal velocity divergence (HD) is known as vertical water vapor advection (VA) (vertical integration divergence of moisture flux (VIDMF)) is given by

$$
H D=\frac{1}{g} \int_{S}^{T} q \nabla \cdot \mathbf{V d p}=\mathrm{VA}
$$

The total moisture budget (moisture flux divergence (MFD)) is calculated by equation 9 .

$$
M F D=H A+H D=\frac{O F}{A}-\frac{I F}{A}
$$

where $\mathrm{A}$ is the bounded area, OF is water vapor mass outflow and IF is water vapor mass inflow [33].

$$
E-P=\frac{O F}{A}-\frac{I F}{A}+p w
$$

where $\mathrm{Pw}$ is storage term, its amount is negligible, therefore equation 10 written as

$$
E-P=\frac{O F}{A}-\frac{I F}{A}=H A+H D
$$

The left side of equation 11which is E-P (flux) obtained from both in situ and ECMWF reanalysis data and the right side of equation 11 calculated from equation 7 and 8 .

The recycling ratio $(\mathrm{R})$ is calculated by

$$
\mathrm{R}=\frac{E}{E+\frac{I F}{A}} \approx \frac{E}{P+E}
$$

The physical meaning of $\mathrm{R}$ is that, it refers to the process of evapotranspiration or evaporation (E) from a given area contributes to precipitation $(\mathrm{P})$ over the same area [10].

\section{Result and Discussion}

Lake Tana, Nile River and other many tributary rivers over the study area can have a definite influence on the local evaporation and boundary moistures.

\subsection{Comparison of reanalysis ECMWF ERA-interim and satellite based precipitation products against the gauge observation}


Time series pattern of rainfall from 2000-2014 is characterized from satellite (CRU and CMAP), reanalysis model products (ECMWF) and the gauge direct measurement as shown in Figure 2. Verification and qualitative comparison of the time series pattern among the satellite and reanalysis data against the gauge is described. Since, the gauge is a reference data at a point measurement they are useful for evaluating ECMWF reanalysis and satellite observational data.
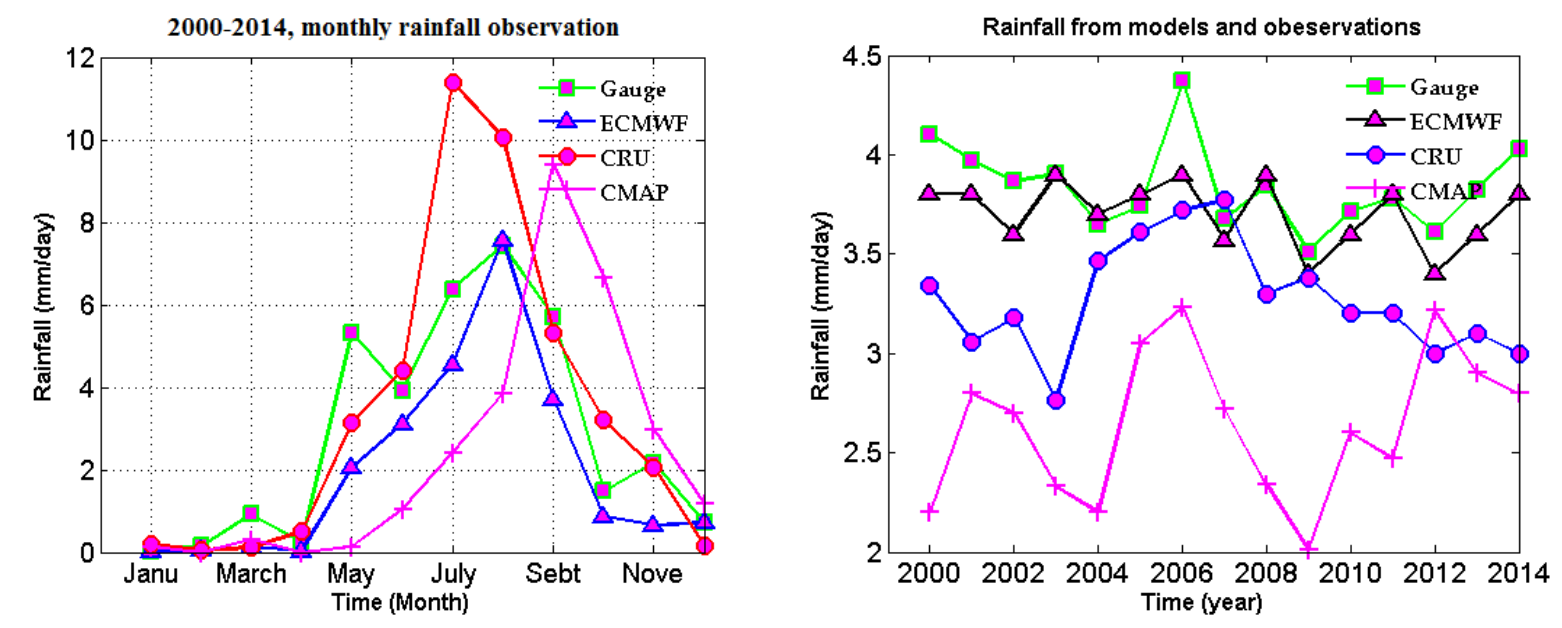

Figure 2. Comparisons of reanalysis products and satellite observation gridded data against the rain gauge data.

As shown in the left panel of Figure 2 the monthly comparisons between ECMWF and satellite precipitation data against the gauge measurements whereas the right panel of Figure 2 indicates annual comparisons of reanalysis and satellite precipitation data and the gauge observation. The long term daily areal mean of precipitation from gauge, CRU, CMAP, and ECMWF are found $3.81,3.32,2.53$ and $3.78 \mathrm{~mm}$ per day respectively. CRU observation rainfall data has good performance with the gauge direct observation except July and August. In July and August the gauge direct observation was 6.2 and $7 \mathrm{~mm}$ per day respectively. While in the CRU estimation was 11.3 and $10 \mathrm{~mm}$ per day respectively. In those months the deviation of CRU rainfall data from the gauge observation was 5.1 and 3.0 respectively (see the left panel of Figure 2). CRU data is sensitive during rainy season over the study area. Inter annual observation of CRU data has less numerical value with compared to the gauge observation as shown the right panel of Figure 2. In monthly observation the peak precipitation value is shifted to September in CMAP observation, whereas in annual CMAP precipitation products were less than the gauge direct observation. Therefore, the CMAP precipitation observation is not good representative over UBNB as we can 
see the left and the right panel of Figure 2. It showed that the monthly and annually means of precipitation from ECMWF is quite similar to the gauge observation. However, there is a difference in amount of the peak precipitation in the gauge as compared to ECMWF. This deviation is occurred due to spars and irregular distribution of gauge stations over the study area. The mean value of the error metrics (Bias, MRE, RMSE and R) are estimated as shown in Table 1.

\section{Table 1}

The comparison between reanalysis and satellite data against gauge data from December to November (2000-2014)

\begin{tabular}{|c|c|c|c|c|c|c|}
\hline & Gauge & Bias & MRE & & RMSE & $\mathrm{R}$ \\
\hline & ECMWF & 0.98 & -0.11 & & 0.87 & \\
\hline 0.72 & & CRU & 1.02 & 0.20 & & 1.03 \\
\hline \multicolumn{7}{|l|}{0.51} \\
\hline & CMAP & 1.12 & 1.20 & & 1.09 & 0.38 \\
\hline
\end{tabular}

The correlation coefficients of precipitation $(\mathrm{P})$ from the gauge and ECMWF is found 0.72, whereas with CRU was 0.51, and CMAP was 0.38. The Bias, MRE, RMSE that generated between gauge and ECMWF are found 0.98, -0.11 and 0.89 respectively. Gauge with CRU is found 1.02, 0.20 and 1.03 respectively. Similarly gauge with CMAP was $1.12,1.20$ and 1.09 respectively. The results indicated that CMAP precipitation data has poor performance as compared to the rest data sets based on the gauge observation data as shown in Table 1. The graphical representation of the error is provided in Figure 3. 

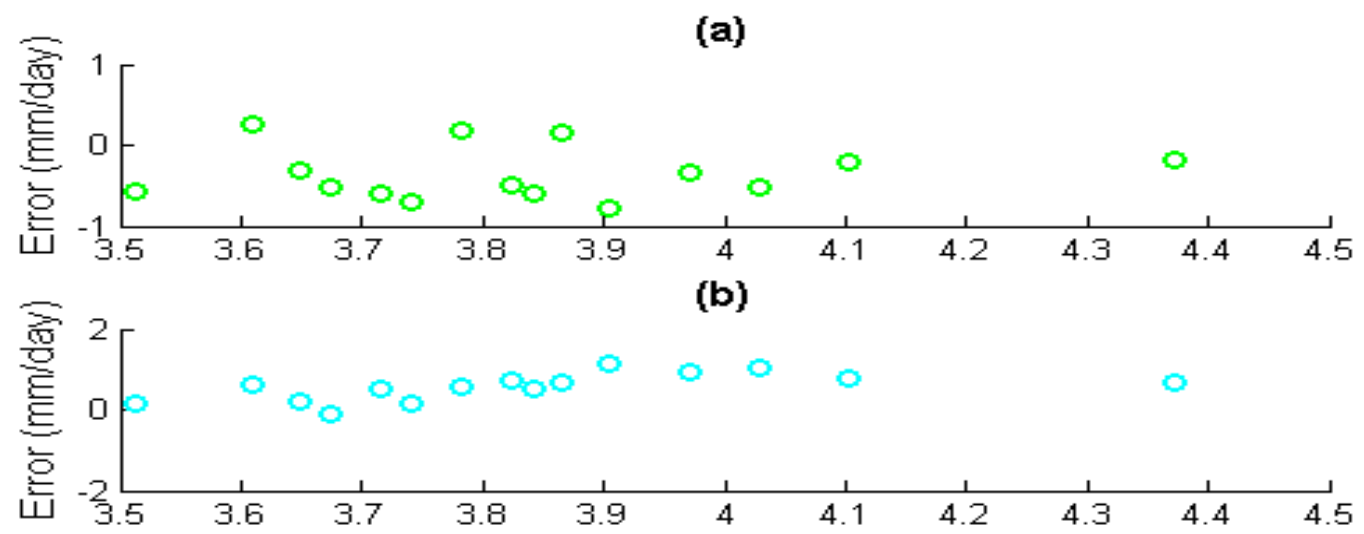

(c)

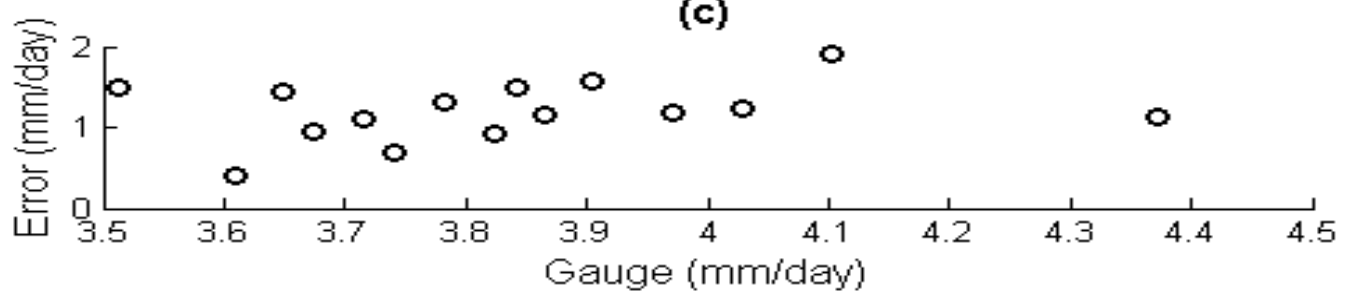

Figure 3. The error deviation from the gauge direct measurements minus reanalysis and satellite precipitation observation.

The error deviation is calculated from the spatial average value of the rain gauge observation minus ECMWF reanalysis data is varied from -1.0 to $0.5 \mathrm{~mm}$ with an average of $-0.11 \mathrm{~mm}$ (see Figure 3 in part a and MRE at Table 1). Whereas between the gauge and CMAP is varied from - 0.5 to 1.1 $\mathrm{mm}$ with an average of $0.2 \mathrm{~mm}$. Similarly, with CRU varied from 0.2 to $2.0 \mathrm{~mm}$ with an average of $1.2 \mathrm{~mm}$ as shown the middle and bottom panel of Figure 3 in part b and c respectively. The minimum error deviation is occurred between gauge and ECMWF reanalysis precipitation data (Figure 3 in part a). The study conducted by [6] over UBNB indicated that the error deviation between assimilation model precipitation results from TRMM and CRU against in-situ measurements were 12 percent. But, in this study the percent of relative error precipitation data between the gauge measurement and ECMWF reanalysis product was 11 percent. Therefore, we concluded that ECMWF data is well representative of in-situ observations over the study domain. Hence, in this paper ECMWF reanalysis gridded model data is widely used for moisture budget study.

3.2.The performance of ECMWF ERA-interim precipitation data against weather radar $\mathrm{Z}-\mathrm{R}$ relation model data 

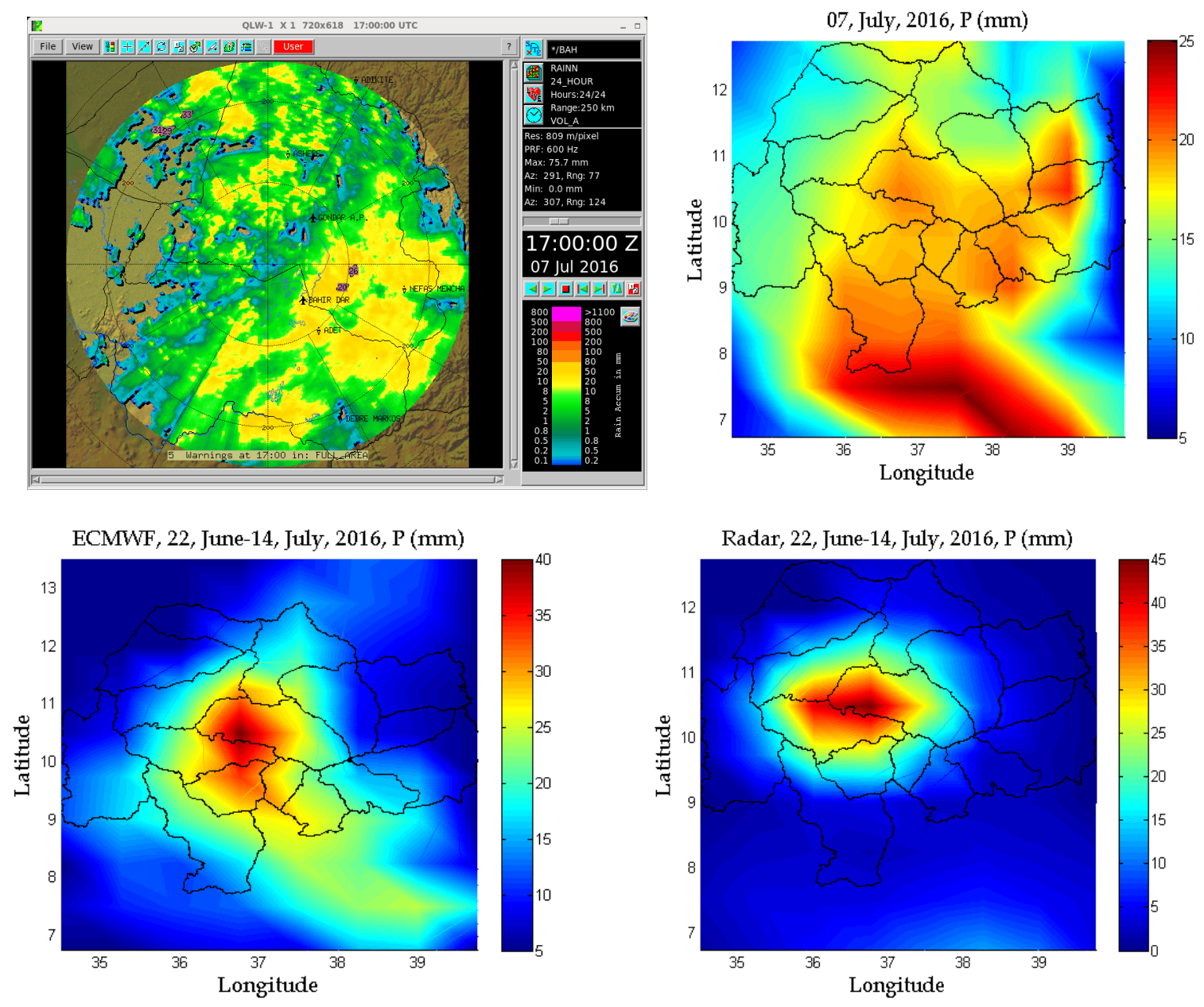

Figure 4. Comparisons between ECMWF and Z-R relation model precipitation data from 22, June, 2016 to14, July, 2016.

The left top panel in Figure 4 depicts the spatial distributions of rainfall estimation from the radar Z-R relation model using IRIS software. While, in the right top panel of Figure 4 is depicts from ECMWF ERA-interim precipitation data using MATLAB software on 07, July, 2016. The radar is installed on 11.10 latitude and 37.40 longitudes. It scans precipitation in the radius of $250 \mathrm{~km}$ in constant altitude plane position indicator products (CAPPI). Therefore, it covers $8.8 \mathrm{~N}$ to $13.00 \mathrm{~N}$ and $34.4 \mathrm{E}$ to $39.2 \mathrm{E}$ degrees. In this domain, the maximum amount of rainfall is found in the southern and the eastern parts of the radar with an estimated value of $26 \mathrm{~mm}$ from Z-R relation model. Similarly, from ECMWF data the maximum amount of rainfall is found in the southern and eastern parts of UBNB within the radar domain with an estimated value of $23 \mathrm{~mm}$ (see the top left and right panel of Figure 4). Furthermore, the western parts of the radar there is no rain 
observation because of the ground clutters the transmitted signal is reflected back to near the radar receiver before reaches the farther rainfall targets. The range of estimated rainfall from the radar Z-R relation model is varied from 2-26 mm with the spatial average value of $16.20 \mathrm{~mm}$ while, ECMWF ERA-interim is varied from 5-23 $\mathrm{mm}$ with spatial average value of $15.40 \mathrm{~mm}$. The bias ratio and mean relative error between ECMWF and Z-R relation model are found 0.95 and 0.05 respectively. The spatial correlation coefficient of rainfall from the radar Z-R relation model and ECMWF was 0.76. This suggests better relationship between them.

For further investigation, a cross-comparison of rainfall from the radar Z-R relation model and ECMWF ERA-interim reanalysis data is also performed (see the bottom right and left panel of Figure 4). The 23 coincident day data from 22, June, 2016 to 14, July, 2016 is obtained from the radar and ECMWF reanalysis depend on the availability of the radar data. The bottom right and left panel of Figure 4 both are illustrated using MATLAB software. The range of rainfall from ECMWF ERA-interim is varied from 5-34 mm with spatiotemporal average value of $20.01 \mathrm{~mm}$. While Z-R relation model from the radar is varied from $2.10-36.30 \mathrm{~mm}$ with spatiotemporal average value of $20.50 \mathrm{~mm}$. The average difference between them was $0.49 \mathrm{~mm}$. It has good performance as we considered a short period of data. The long year precipitation data average difference between gauge and ECMWF is 0.11(see Figure 3). Hence, gauge and ECMWF is better agreement than weather radar Z-R relation model and ECMWF. This is suggesting that, the absolute difference of precipitation from the radar Z-R relation model and ECMWF is bounded within $49 \%$.

\subsection{Seasonal variation of atmospheric moisture budgets over the research domain}



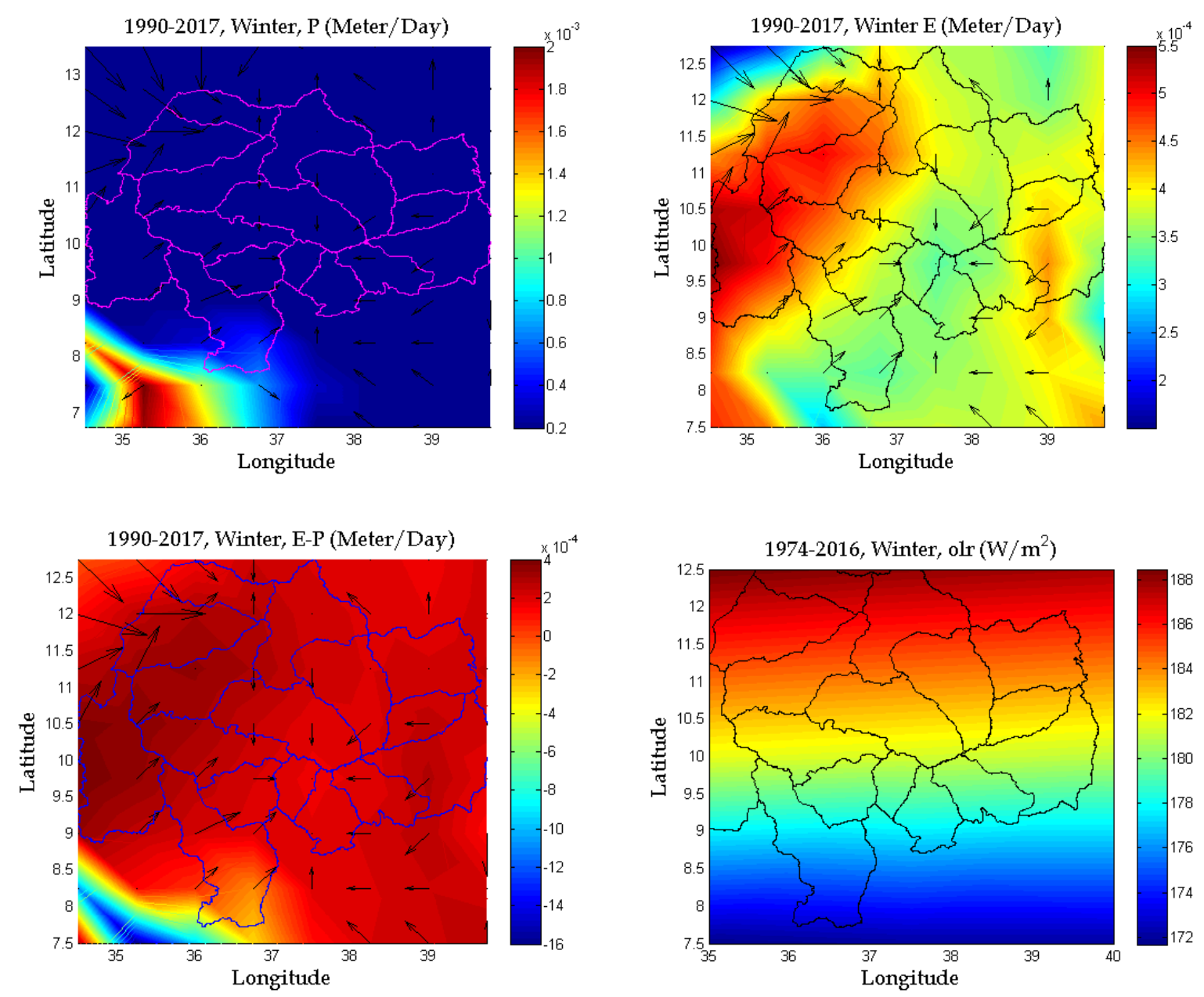

Figure 5. Winter P, E, E-P and OLR distribution from 1990-2017.

The black arrowhead on the spatial distribution plots are indicated the wind vectors. The tail of the arrow indicated high pressure gradient forces whereas the arrow head indicated the low pressure gradient forces as shown in Figure 5. During the winter season, the southern part of the study area the intensity of OLR is less in amounts; because it traps by the local moistures. In the southern parts of the study area the intensity of precipitation larger than the strength of the wind vectors, similarly the winds were divergence at this location. Those indicators were good evidence the precipitation that comes from the local (study area) moistures (Figure 5). The numerical value of recycling ratio was $35.30 \%$ during the winter season (Table 3). During the winter, spatial and temporal average of precipitation was $0.5 \mathrm{~mm}$ per day, while evaporation was $0.4 \mathrm{~mm}$ per day. 
Similarly, the flux (E-P) varied from -0.64 to $0.12 \mathrm{~mm}$ per day with an average of $-0.08 \mathrm{~mm}$ per day as shown in Figure 2.

As depicted in Figure 6, the spring season (Belg), the Indian Ocean moisture budget is quite useful for UBNB climate system and hydrological cycle.
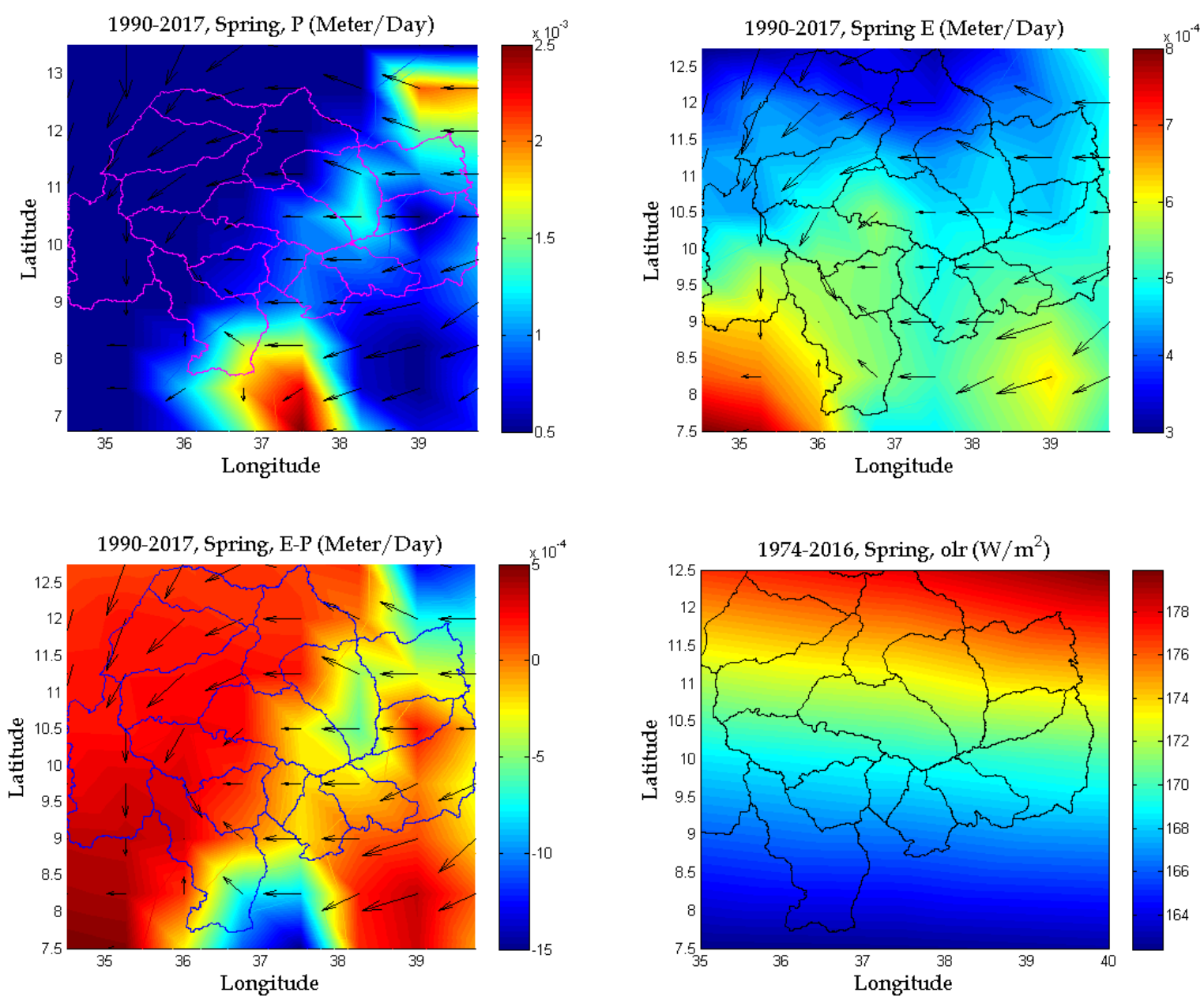

Figure 6. During spring P, E, E-P and OLR distribution from 1990-2017.

During spring, the moisture flux was mostly westward over UBNB as shown the wind patterns on the precipitation system in Figure 6, but exactly opposite with a northeastward component in the summer season refer in Figure 7. In spring and autumn the wind vectors over UBNB was strong as compared to the winter and summer season (Figures 5 and 7). During spring season, the western part of the earth tilts towards the sun. Therefore, the maximum amount of pressure gradient force is created over the Indian Ocean [34]. So that, the winds blows from east to west. Hence, eastern 
part of the study area got precipitation (rainfall) from Indian Ocean but not from the local moistures. Because the wind strength and the precipitation intensity were proportional and OLR distribution was similar from east to west. We can identify easily from the precipitation and OLR distribution in Figure 6. However, the southern parts of the research domain received additional $(19.01 \%)$ precipitation from the locale moistures as indicated recycling ratio in Table 3. Moreover, the western part of the study area didn't receive sufficient rainfall. Because, central part of the study area has mountainous topography that blocks the western parts from the easterly moistures. In this season, the range of precipitation is varied from 0.5 to $1.7 \mathrm{~mm}$ per day with an average of $1 \mathrm{~mm}$ per day and evaporation is varied from 0.52 to $0.6 \mathrm{~mm}$ per day with an average of $0.5 \mathrm{~mm}$ per day. Whereas the flux, is varied from -1.09 to $0.02 \mathrm{~mm}$ per day with an average of $0.01 \mathrm{~mm}$ per day (Figure 6).

The Atlantic Ocean moisture budget is very important component for Ethiopian precipitation distribution during the summer season [15]. Similarly, this finding is strongly supported reference [15] we can see in Figure 7. The intensity of precipitation distribution at the central part of the study area is strong as compared to the surrounding area as shown the top left panel of Figure 7.
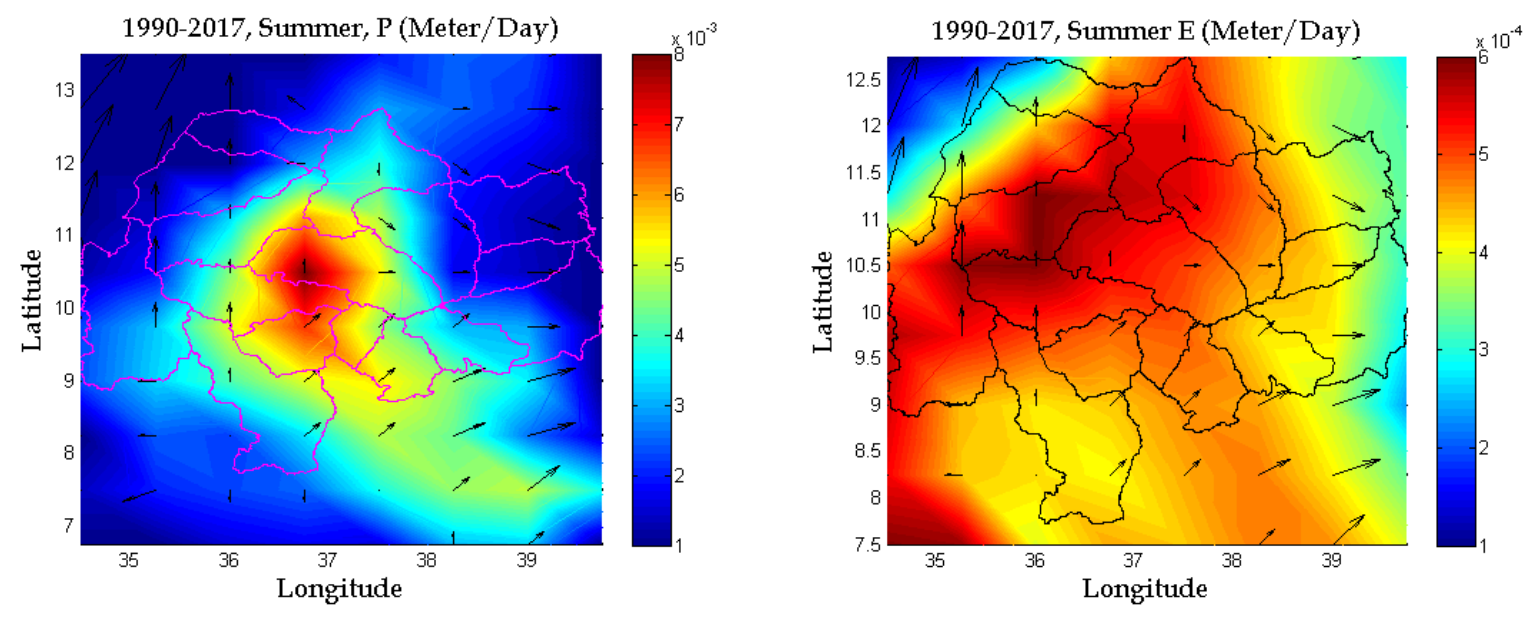

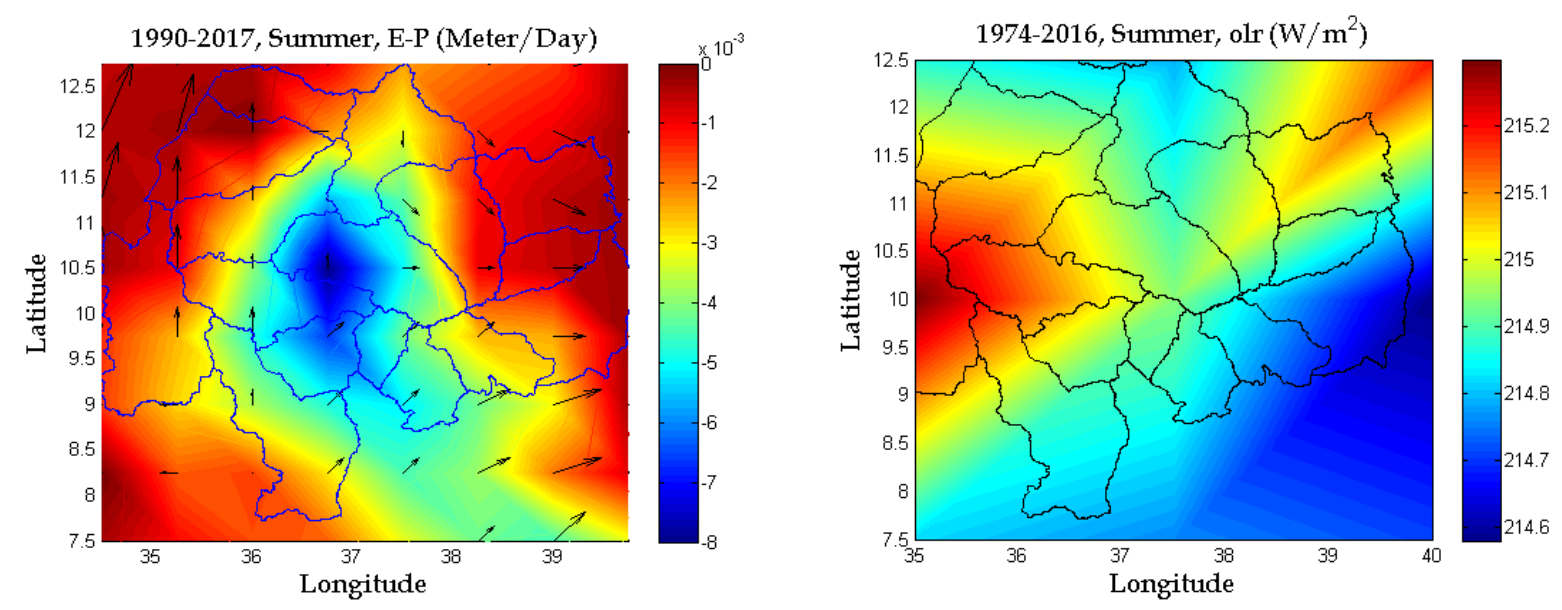

Figure 7. Summer P, E, E-P and OLR distribution from 1990-2017.

The Lake Tana and Abay basin are a moisture divergence zone which is the contribution of net moisture from the water body to the surrounding atmospheric regions. As a result, the amount of precipitation intensity became strong at the central parts of the study area with estimated value of $8.0 \mathrm{~mm}$. The wind vectors did not proportional to the precipitation in the central parts of the study area and OLR became decrease. Which one can observe the recycling ratio, the study area moisture contributed $9.70 \%$ of precipitation in addition to Atlantic Ocean moistures as shown in the top left panel of precipitation and bottom right panel of OLR in Figure 7. Previous studies have indicated that Atlantic-related moistures over Ethiopian summer precipitation contribution are stronger than the Indian Ocean $[15,16]$. But in contrast, the study conducted by Ellen and Asgeir [26] is stated that during the summer season, Indian Ocean moisture more contributed precipitation than Atlantic Ocean moistures over Ethiopian highlands. Our finding clearly supports the references [15, 16]. In rainy season, the average value of precipitation, evaporation and the flux was 4.2, 0.5 and -3.6 mm per day respectively (Figure 7). During the summer season, precipitation value much larger than evaporation and the flux highly deviates to the negative value. 

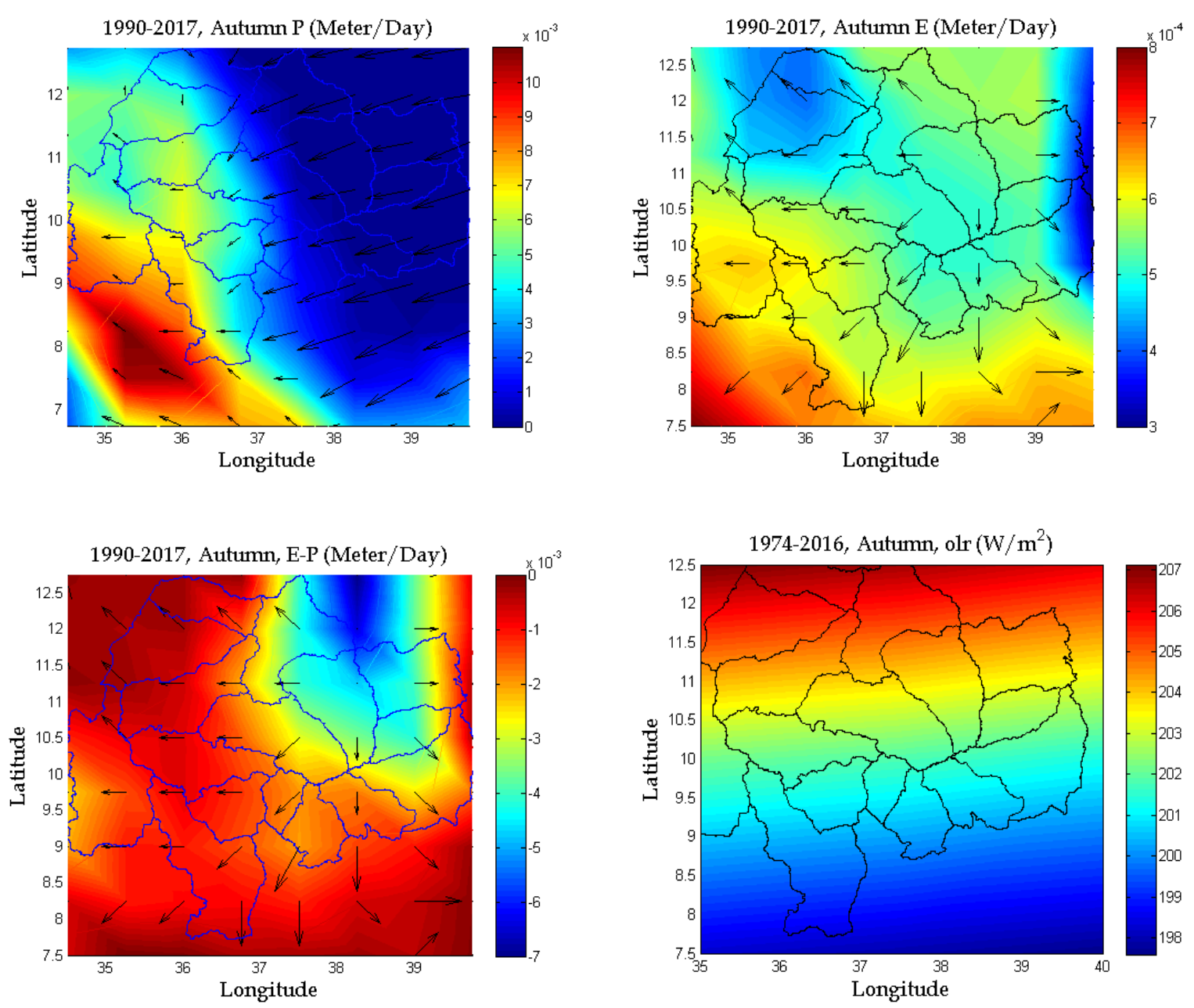

Figure 8. Autumn P, E, E-P and OLR distribution from 1990-2017.

During autumn, the range of precipitation is varied from 0.5 to $7 \mathrm{~mm}$ per day with an average of $2.2 \mathrm{~mm}$ per day while evaporation is varied from 0.5 to $0.8 \mathrm{~mm}$ per day with an average of $0.7 \mathrm{~mm}$ per day. Similarly, the flux is varied from -6 to $0 \mathrm{~mm}$ per day with an average of $-1.4 \mathrm{~mm}$ per day. The mean net moisture flux through the northern Ethiopian highlands (UBNB) is northeasterly. The $83.67 \%$ of autumn precipitation is coming from the large scale moisture dynamics such as Indian Ocean, the Gulf of Guinea, Congo basin, Mediterranean Sea, the Arabian Peninsula, the Red Sea and $16.33 \%$ coming from the small scale moisture dynamics (the local moistures). We can see the wind vectors at the top left panel of Figure 8. It supported to Mariotti et al. [35] and Korecha and Barnston [15] findings. But, Ellen and Asgeir [26] stated that Mediterranean Sea, the Arabian Peninsula and the Red Sea moistures contributed precipitation during summer season. Ellen and Asgeir [26] are not considered the study area moistures that influenced the summer 
season precipitation dynamics and their finding are far from the physics principle. According to the law of natural dynamics, during the summer season the earth`s northern hemisphere tilts towards the sun and received maximum radiations. As a result, high pressure gradient forces are created in the southern hemisphere. Therefore, moisture carrying winds originated from the southern hemisphere Atlantic Ocean to the northern hemisphere and to Ethiopia. To this end, Ethiopian highlands such as UBNB has got precipitation due to the mountainous topography that upwelling the moisture carrying winds from advection to convection. Our finding is also gives strong support to this natural phenomenon as we can see in Figure 7.

\subsection{Annual precipitation and evaporation distributions}

Annual precipitation distribution is increased from northeast to southwest. In this study, the spatial distribution of precipitation has good agreement with the study conducted by [7, 28] over UBNB. The 38 years annual mean of precipitation in winter, spring, summer and autumn separately over UBNB are found 146.00, 547.50, 2007.45 and $1460.10 \mathrm{~mm}$ respectively. Whereas, E was 175.20, 189.52, 200.75 and $182.5 \mathrm{~mm}$ respectively (Table 2).

Table 2. Seasonal and annual precipitation and evaporation amounts.

\begin{tabular}{llclll}
\hline Parameter & Winter & Spring & Summer & Autumn & Annual \\
\hline P $(\mathrm{mm})$ & 146.00 & 547.50 & 2007.45 & 1460.10 & 1040.25 \\
E $(\mathrm{mm})$ & 175.20 & 189.52 & 200.75 & 182.50 & 189.24 \\
\hline
\end{tabular}

The mean annual precipitation and evaporation is found to be $1040.25 \mathrm{~mm}$ and $189.24 \mathrm{~mm}$ respectively (Table 2). The study conducted by Conway [27] using station data over UBNB, the mean annual precipitation and evaporation is found $1200 \mathrm{~mm}$ and $200 \mathrm{~mm}$ respectively. Our finding, precipitation and evaporation data from ECMWF is slightly less than Conway [27] finding. The main reason, Conway used to in-situ data to estimate precipitation and evaporation. But, in-situ measurements over UBNB are sparsely and irregularly distributed and also within this region remote area such as Sudan's border there is no station distributions [7]. Therefore, to estimate precipitation and evaporation with the required spatial and temporal resolution is impossible. Because of this, the small deviation is occurred between Conway and our finding. The 
annual mean of precipitation was much sharper gradients in southwest parts whereas evaporation was strong in the northwest parts as shown the left and the right top panel of Figure 9 respectively.
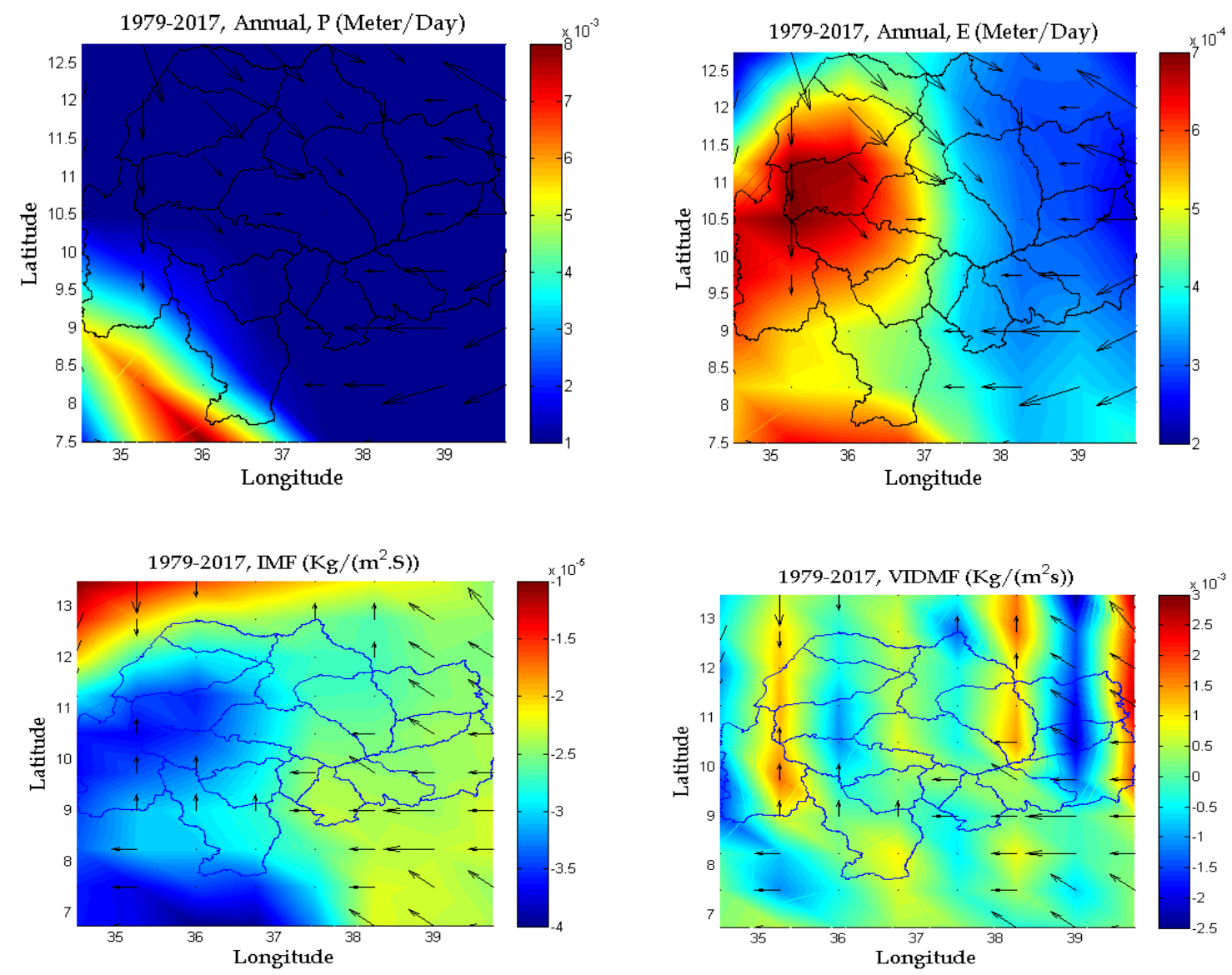

Figure 9. Annual P, E, IMF and VIDMF distribution from 1979-2017 over the study area.

In the northwest parts of the study area the wind vectors are directed towards the southern parts. Another easterly winds are directed to the western parts (see top right panel of Figure 9). The two air masses converge together in the southwest parts and it formed clouds over the study domain. Therefore, southwest parts of the study area are received maximum annual rainfall with compared to the remaining parts of the study area. The instantaneous moisture flux (IMF) is maximum at the southwest parts of the study area; as shown the negative legend numerical values over bottom left panel of Figure 9. It is strong evidences for the dependence of annual precipitation and the amount of IMF that available in the region and the effectiveness of this water vapor is condensed and form clouds which subsequent precipitation. Comparing the IMF and VIDMF in the left and right panel 
of Figure 9 with the precipitation and evaporation in the top left and right panel of Figure 9 were proportional.

\subsection{Recycling ratio over the study domain}

Recycling ratio for four seasons (summer, autumn, spring and winter) was $9.70 \%, 16.33 \%, 19.01 \%$ and $35.30 \%$ respectively. The maximum amount of precipitation is extracted from the locale moistures during the winter season; it provided in Table 3.

Table 3. Seasonal variation of recycling ratio over UPNB both water bodies and the land from 1979-2017.

\begin{tabular}{lc}
\hline Seasons & Percent $(\%)$ \\
\hline December-February (Winter) & 35.30 \\
March-May (spring) & 19.01 \\
June-August (summer) & 09.70 \\
September-November (autumn) & 16.33 \\
Annual & 20.11 \\
\hline
\end{tabular}

Recycling ratio is decreased as increased precipitation category and evaporation is increased partially with precipitation category (Table 3). Based on equation 12, the estimated value of precipitation is increased; we can expect a minimum value of recycling ratio. Which means the value of the total inflow should be much larger than evaporation. It indirectly proves that the large scale moisture dynamics is supported a significant precipitation especially in summer large precipitation events over the study domain. Even though, large precipitation events provided from global moistures, the central parts of the study area has got precipitation from local (study area moistures (see P in Figure 7) with estimated value of recycling ratio was 9.7\%. Northeast parts of UBNB has got precipitation from local moistures in autumn season with estimated value of recycling ratio was $16.33 \%$. Annual recycling ratio over the study domain is $20.01 \%$ which was far less than Fengjun et al. [10] finding of 55\% but slightly larger than Jin and Zangvil [23], finding in which they got $18 \%$ over the Mediterranean region. Recycling ratio is usually increased with the increment of the size of research domain, while the characteristic of surface cover is kept similar [10]. Several studies have reported that the size of the research domain has a crucial 
influence of moisture budget studies [10,23]. A larger area better represents the reality of largescale moisture budget fields. The minimum area required for moisture budget study is $1 \times 10^{5} \mathrm{~km}^{2}$ [36]. Since our research area is slightly larger than the minimum required for moisture budget study $\left(1.76 \times 10^{5} \mathrm{~km}^{2}\right)$.

Generally, the study area moistures act a less contribution of precipitation over the research domain. But, it was a considerable role which contributes $79 \%$ of precipitation to the surrounding countries such as Egypt and Sudan as shown the moisture filed vectors in Figures 5, 6, 7 and 8. We expect that the renascence dam which under construction now, if it is finished downstream countries such as Egypt and Sudan they will get a high amount of precipitation from UBNB moistures. Hence this dam has positive impacts for downstream countries to supply moistures for the precipitation system. Even though, the study area moisture budget did not that much significant for the contribution of precipitation over the research area like other downstream countries; it was substantially useful to supply winter precipitation. These local moistures are originated from Lake Tana, Abay basin, tributary rivers, forest covers and soil moistures. We expected that, in the future, recycling ratio is less than $20.01 \%$. Because, in the present time Lake Tana going to damage by water hyacinth (Emboch) weeds. Abay basin is also depending on Lake Tana and forest coverage around the basin. Since, Lake Tana contributed the water flow from the Lake to the Nile river basin. Another alarmed issue the soil lost its moisture due to chemical fertilizers, deforestation and over grazing [6, 7, and 27].The local atmospheric moisture is reduced because of the problem is mentioned above. Therefore, in the future recycling ratio is reduced due to insufficient moistures in the surrounding atmosphere.

\section{Conclusions and Recommendations}

Moisture budget studies are a basic tool to understand dynamical, hydrological and climatological aspects of atmospheric research. During the summer season, the moisture flux is directed mostly eastward over UBNB, but in spring and autumn seasons are directed westward and transported moistures from Indian Ocean. During the winter season study area moisture contributed the highest amount of precipitation with relative to other seasons, especially at southwest parts of the study area. The southern part of UBNB is received precipitation throughout the year, during dry season from local moistures and during rainy season from global moistures. Recycling ratio is varied from $9.7 \%$ to $35.30 \%$ with an average of $20.11 \%$. The local evaporated moisture is less contributed of 
precipitation over UBNB region rather than it contributes around $79 \%$ to neighboring countries such as Egypt and Sudan. From our analysis we understand that after renascence dam is constructed around UBNB region, downstream countries will get a high amount of precipitation from the dam and the total Abay basin moistures. Therefore this dam has the positive impact on downstream countries. We expect that in the near future recycling ratio is going to be reduced, because Lake Tana going to damaged by water hyacinth (Emboch) weeds. Abay basin is also depending on Lake Tana and forest coverage around the basin. The soil is lost its moisture due to chemical fertilizers, deforestation and over grazing. From this result we recommended that, Ethiopia and downstream countries meteorologists and hydrologists as well as the society collaboration with the government should be mitigated the climate conditions and to take remedial actions for the problem is stated above. Around the river of UBNB is cover by forest, avoid water hyacinth from Lake Tana, use natural fertilizers instead of chemical fertilizers and to protect the soil moistures are needed over the study domain.

\section{Conflicts of Interest}

The authors declare that there is no conflict of interest regarding the publication of this paper

Acknowledgments: The authors are thankful for constant support by Bahir Dar University, Ethiopia and a partial support from Debre Markos University, Ethiopia. Our gratitude goes to Dr.Dawit Amogne, Dr.Degenie Sahalu and Dr. Melessew Nigusie for their substantial comments and suggestions for this work.

\section{References}

[1] A. R. Ganguly, D. Kumar, P. Ganguli, G. Short and Klausner, "Water Stress on Power Production”, J. Climate Adaptation Informatics: Comput.Sci. Eng. 17, 53-60, 2015.

[2] J. Elliott et al., "Constraints and potentials of future irrigation water availability on agricultural production under climate change", Proc. Natl. Acad. Sci. USA 111, 32393244, 2013.

[3] D. Pimentel, B. Berger, D. Filiberto, M. Newton, B. Wolfe, E. Karabinakis, S. Clark, E. Poon, E. Abbett and S. Nandagopal, "Water resources: agricultural and environmental issues", BioScience, 54, 909-918, 2004.

[4] R.M. Johnston and M. McCartney, "Inventory of water storage types in the Blue Nile and Volta river basins”, IWMI, Working paper.140, 2010. 
[5] O. Charles and W. Patrick, "Spatial and temporal variability of rainfall in the Nile Basin”, Hydrol. Earth Syst. Sci. 19, 2227-2246, 2015.

[6] M.M. Allam, A. JainFigueroa, D. B. McLaughlin and E. A. B. Eltahir, "Estimation of evaporation over the upper Blue Nile basin by combining observations from satellites and river flow gauges", AGU, Water Resour. Res., 52, doi:10.1002/2015WR017251, 2016.

[7] W. Abera, F. Giuseppe, B. Luca and R. Riccardo, "Water budget modeling of the Upper Blue Nile basin using the JGrass-NewAge model system and satellite data", Hydrol. Earth Syst. Sci. Discuss., 2016-290, 2017.

[8] E. Ozsoy, "On the atmospheric factors affecting the Levantine Sea", Tech. Rep. 25, 29

pp., $\quad$ Eur. Cent. For Medium Range Weather Forecasts, Reading, U. K, 1981.

[9] U. Kalim and S. GAO, "Moisture Transport over the Arabian Sea Associated with Summer Rainfall over Pakistan in 1994 and 2002", ADVANCES IN ATMOSPHERIC SCIENCES, VOL. 29, NO. 3, 501-508, 2012.

[10] J. Fengjun, K. Akio and A. Pinhas, "Climatological relationships among the moisture budget components and rainfall amounts over the Mediterranean based on a super-high- resolution climate model", Journal of geophysical research, vol. 116. D09102, doi: $\quad$ 10.1029/2010JD014021, 2011.

[11] E.S. Dawn, P. Amey and G. Subimal, "Use of Atmospheric Budget to Reduce Uncertainty in Estimated Water Availability over South Asia from Different Reanalysis", Scientific Reports/6:29664 / DOI: 10.1038/srep29664, 2016.

[12] J. Peter and H. Diane, "Investigation of Large-Scale Atmospheric Moisture Budget and Land Surface Interactions over U.S. Southern Great Plains including for CLASIC (June 2007)", LAMB E T AL, 1719-1738, 2012.

[13] A. Zangvil, D. Portis and P. Lamb, "Investigation of the large-scale atmospheric moisture field over the Midwestern United States in relation to summer precipitation. Part I: Relationships between moisture budget components on different timescales", J. Climate 14, 582-597, 2001.

[14] Z. Zengxin, Z. Qiang, Xu. Chongyu, L. Chunling and J.Tong, “Atmospheric moisture budget and floods in the Yangtze River basin, China”, Theor Appl Climatol. 95, 331-340, 2009.

[15] D. Korecha and A. G. Barnston, "Predictability of June-September Rainfall in Ethiopia”, Monthly Weather Review, 135(2): 628-650, 2007. 
[16] Z.T. Segele, P. J. Lamb, et al., "Large-scale atmospheric circulation and global sea surface temperature associations with Horn of Africa June-September rainfall", International Journal of Climatology, 29(8): 1075-1100, 2009.

[17] L. Ogallo and M. Halpert, "Tele-connections between seasonal rainfall over East Africa and global sea surface temperature anomalies", Journal of the MeteorologicalSociety of Japan 66, 807-821, 1988.

[18] H. Joanna, "Solar influences on Climate. Grantham Institute for Climate Change Briefing”, $\quad$ paper No 5: www.imperial.ac.uk/climatechange/publications, 2011.

[19] K.N. Liou, "Introduction to atmospheric radiation: Second edition", International Geophysics series, Vol. 84, 2002.

[20] K.E. Trenberth, "The definition of El Nino", Bulletin of the American Meteorological Society 78, 2771-2777, 1997.

[21] B. Emily, S. Julia and R. Kenneth, "An Observational Study of the Relationship between excessively Strong Short Rains in Coastal East Africa and Indian Ocean SST, Monthly Weather Review”, AMS. 131, 74-94, 2003.

[22] Li.Sun, B. SHEN, Z. GAO, B. SUI, B. Lesheng and W. LIJian, "The Impacts of Moisture Transport of East Asian Monsoon on Summer Precipitation in Northeast China", ADVANCES IN ATMOSPHERIC SCIENCES, VOL. 24, NO. 4, 606-618, 2007.

[23] F.J.Jin and A. Zangvil, "Relationship between moisture budget components over the eastern Mediterranean”, Int. J. Climatol. 30(5), 733-742, 2010.

[24] A. Drumond, J. Marengo, T. Ambrizzi, R. Nieto, L. Moreira and L. Gimeno, "The role of the Amazon Basin moisture in the atmospheric branch of the hydrological cycle:

a Lagrangian analysis”, Hydrol. Earth Syst. Sci., 18, 2577-2598, 2014.

[25] P. Catherine, K.Yochanan and G. Alessandra, "Moisture budget analysis of SSTdriven decadal Sahel precipitation variability in the twentieth century", Clim Dyn. 44, 3303- 3321, 2014.

[26] V. Ellen and S. Asgeir, "The Effect of Moisture Transport Variability on Ethiopian Summer Precipitation", International Journal of Climatology, DOI: 10.1002/joc.3566, 2013.

[27] D. Conway, "The climate and hydrology of the Upper Blue Nile River", Geographical Journal. pp, 49-62, 2000.

[28] M. Mariam, J. Anjuli, B.Dennis and A. Elfatih, "Estimation of evaporation over the upper Blue Nile basin by combining observations from satellites and river flow gauges", AGU, Vol. 52(2), 644-659, 2016. 
[29] D. Sahalu, I. Efthymios, A. Semu, N. Emmanouil and D. Hailu, "First Evaluation of the Day-1 IMERG over the Upper Blue Nile Basin", American Meteorological Society, JOURNAL OF HYDROMETEOROLOGY VOL. 17, 2879-2882, 2016.

[30] P. Kallberg, A. Simmons, S. Uppala and M. Fuentes, "The ERA-40 Archive, ERA40 Project Report Series No. 17 , European Centre for Medium-range Weather Forecast”, $\quad$ Reading, UK; 31, 2004.

[31] P. Berrisford, P.W. Kallberg, S. Kobayashi, D.P. Dee, S. Uppala, A. Simmons, P. Poli and H. Sato, "Atmospheric conservation properties in ERA-Interim", Quart. J. Roy. Meteor. Soc.137, 1381-1399, 2011a.

—, and Coauthors, "The ERA-Interim archive version 2.0. European Centre for Medium-Range Weather Forecasts ERA”, Rep. 1: 23 pp, 2011 b.

[32] D. Dee and Coauthors, "The ERA-Interim reanalysis: Configuration and performance of the data assimilation system”, Quart. J. Roy. Meteor. Soc. 137, 553-597, 2011.

[33] A. Zangvil, D.H. Portis and P.J. Lamb, "Investigation of the large-scale moisture field over the Midwestern United States in relation to summer precipitation. Part 2: $\quad$ Recycling of local evapotranspiration and association with soil moisture and crop yields", J. Clim. 17, 3283-3301, 2004.

[34] A. Mariotti, M.V. Struglia, N. Zeng and K.M. Lau, "The hydrological cycle in the Mediterranean region and implications for the water budget of the Mediterranean Sea", J. $\quad$ Climate 15, 1674-1690, 2002b.

[35] P.Yeh, M. Irizarry and E. Eltahir, "Hydroclimatology of Illinois: A comparison of monthly evaporation estimates based on atmospheric water balance and soil water balance", J. Geophys. Res. 103, 19: 823-19,837, 1998. 